\title{
Uma abordagem corporal na formação do profissional da área da saúde
}

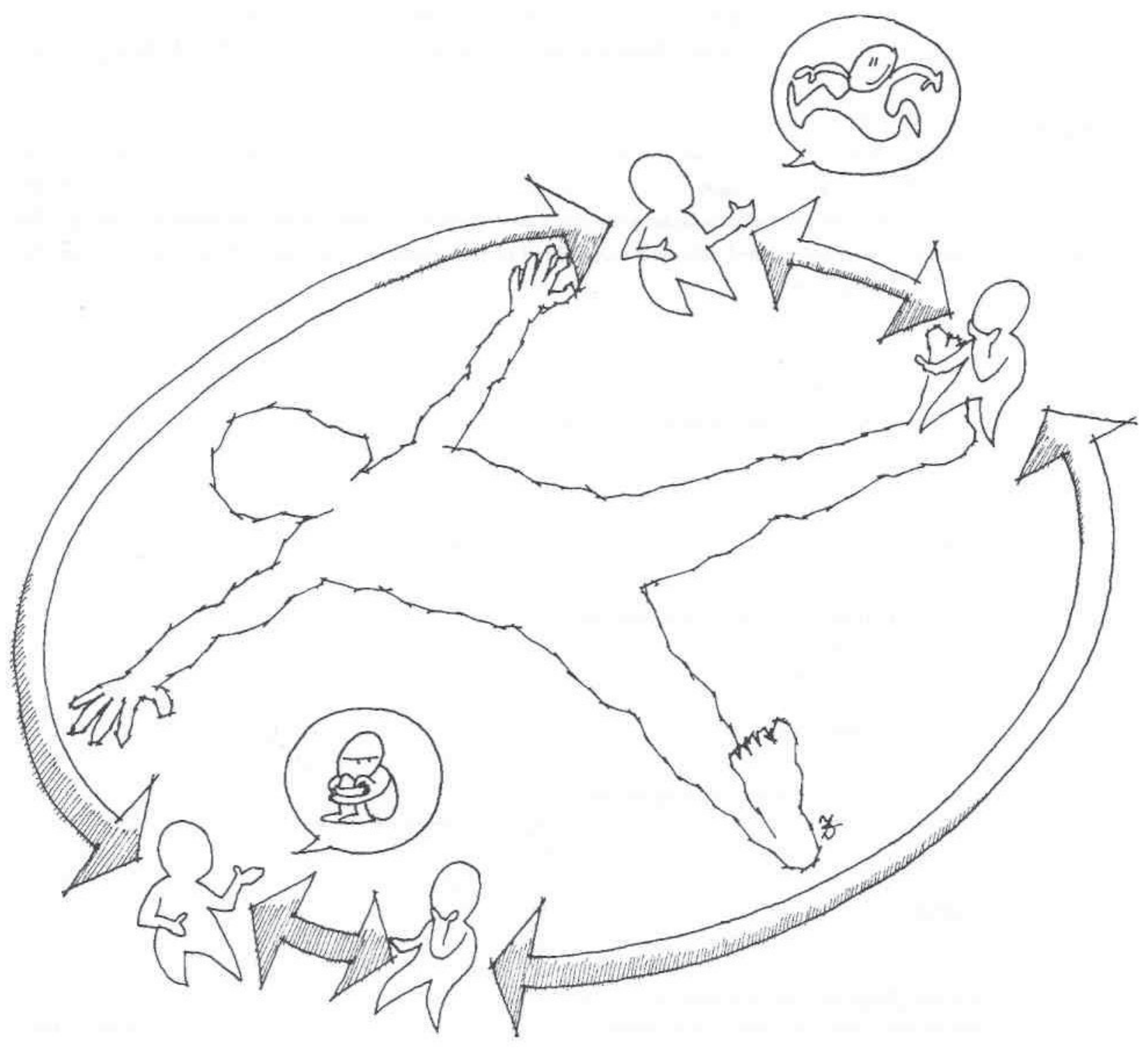




\title{
Resumo
}

"O presente artigo possui como foco principal a reflexão da ação e postura técnica do profissional da área da saúde nas relações humanas. Parte da premissa que a concepção de corpo e o entendimento dos paradigmas do desenvolvimento humano determinam a forma de intervenção e utilização das técnicas aprendidas nas relações interpessoais.

A partir das reflexões sobre o corpo, que esclarece não haver diferença da forma profissional da forma pessoal de concebê-lo, ou seja, que a forma pessoal, o self, está presente nas ações profissionais, busca-se refletir uma abordagem corporal na formação do profissional da saúde focalizando dois aspectos principais. De um lado, entender o gesto humano consciente, racionalizado, juntamente com o gesto inconsciente, por outro, a subjetividade da corporeidade.

A temática em questão pretende resgatar o sentido natural e humano das intervenções profissionais partindo de uma formação que amplia o autoconhecimento, apurando a sensibilidade sobre si e sobre o outro".

\begin{abstract}
The present article has, as the main point, the reflection of the action and the technical position of the professional of the health area in the human relationship. It carnes from the idea that the body conception and the understanding of the human developing concepts determines the intervention way and the using of techniques learnt by the personal relationship.

Since the body reflections means to have no difference between professional and personal way to conceive it and by the way the personal manner "the self" is presenting in the professional actions, a reflection is tried to be made on the body approch given a special focus in two main aspects. First, learning the human gestures in a concious and relational way added to the unconcious gestures. Afterwards, understanding the body subjettivity.

These theme question has the purpose of obtaining the natural and human sense of professional interferences coming from a special formation which enlarge the self learning centered in the sensibility about himself and about someboddy else.
\end{abstract}

\section{REFLEXÕES INICIAIS}

Quando tratamos do assunto abordagem corporal, devemos, antes de tudo, clarear a concepção de corpo que possuímos, para que possamos conduzir a linha de raciocínio no desenvolvimento deste artigo.

Falar do corpo envolve as mais variadas formas de concebê-lo, ou como escreve Santin (1995): Significa repensar o projeto antropológico construído desde os gregos, consagrado pelos teólogos medievais, confirmado pelos filósofos modernos e aceito pelos pensadores contemporâneos (p.91). Não cabe nesse pequeno artigo analisar todas essas temáticas, mas ao menos entender a sua real dimensão. O que podemos constatar de início é o fato de que os conhecimentos sobre o tema "corpo" são limitados e, talvez mesmo, mascarados por estereótipos que deturpam sua compreensão.

Quando falamos em corpo, pretendemos abordá-lo menos sob os seus aspectos anátomo-fisiológicos e mais sob seus aspectos sociocultural e relacionai. Isso significa entender o corpo fora das concepções racionalistas que tentam reduzir a sua totalidade. Abordar o corpo significa necessariamente tratar dos paradigmas do desenvolvimento humano, pois um está amarrado ao outro. Assim, será que podemos, de alguma forma, conceber o pensamento humano dissociado do corpo? Ou for- 
mulando de outra maneira: podemos, em algum momento, pensar sem o corpo?

Neste artigo, que trata de uma abordagem corporal na formação do profissional da área da saúde, é importante entender a visão de corpo que hegemonicamente se instituiu como válida em termos profissionais. Para refletir sobre essa temática, faremos alguns questionamentos sem a preocupação de respostas imediatas, uma vez que as mesmas serão desenvolvidas no curso desse artigo. Sendo assim, se profissionalmente compreendese o corpo como algo separado, segmentado, será que se pode admiti-lo pessoalmente como uno, ou seja, uma totalidade? Para completar, no momento em que se acredita na totalidade do corpo, pode-se ainda questionar: existe diferença da forma pessoal para a forma profissional em conceber o corpo?

Os questionamentos que realizamos fa zem refletir acerca dos paradigmas que tratam do corpo e desenvolvimento humano. Ter a ciência dos paradigmas permite optar por um caminho ou outro nas relações que tratam do desenvolvimento humano. Ora, se entendemos que as áreas da saúde possuem como foco prin cipal o ser humano, a clareza dessa compreen são se torna determinante nas intervenções profissionais, ou seja, tanto de ordem clínica, terapêutica, reeducativa, assistencialista ou ainda educativa. $2 . \% \cdot$

\section{A FoRMAÇ̃̃o PELA VIA CORPORAL}

\subsection{O GESTO HUMANO CONSCIENTE E INCONSCIENTE}

Para podermos refletir sobre a importância de uma formação corporal para o profissional da saúde, é importante entender os pressupostos que norteiam sua realização, que considera a forma de conceber o movimento humano como componente determinante no desenvolvimento humano.

Segundo Negrine (1994), o movimento humano em sua totalidade considera tanto os aspectos funcionais, como também relacionais. É considerado não somente como atividade de exercícios físicos, mas expressão de sentimentos, emoções, manifestações de prazeres e desprazeres, bem como a expressão das potencialidades e fragilidades pessoais. Assim, o movimento humano não pode ser entendido como racional e lógico, mas ao contrário, que possui, acima de tudo, ações desconhecidas, ou melhor, que podem até ser conhecidas, mas que escapam ao domínio consciente.

Sobre isso Levi Strauss, citado por Negrine (1994), afirma que o consciente da mente humana está sempre vazio e receptivo, enquanto que o inconsciente está repleto de imagens. E como um arquivo imenso e desordenado de vivências e experiências adquiridas. Pensar nessa direção permite entender que as vivências que se adquire na história de vida, necessariamente se dá pela via corporal e, por sua vez, registram-se no substrato inconsciente. São as responsáveis por uma ampla parcela do comportamento.

Buscamos apoio na área psicanalítica para explicar que o movimento está intimamente ligado ao pensamento humano, sendo que um não pode estar dissociado do outro. Ressaltamos que não é somente o movimento racionalizado que é expresso através do corpo, mas principalmente o movimento não racional, ou seja, o movimento que não está sob o domínio consciente. Lapierre (1988-A) explica que o gesto corporal é a expressão direta do inconsciente. Reforça ainda:

\footnotetext{
"As sensações corporais estão diretamente ligadas aos centros subcorticais e ao hipotálamo, centro integrador das emoções. Elas tem um poder evocador muito mais poderoso, mais primitivo, mais direto que a linguagem verbal que se elabora no córtex" (p.29).
}

Podemos compreender que a expressão do corpo é significante, como a expressão verbal, e tem com o significado a mesma relação de ambigüidade. Isso quer dizer que o gesto corporal remete para além do significado consciente, ou seja, um significado inconsciente que deve ser decodificado.

Falar da expressão motriz não se limita ao gesto motor, muito menos ao gesto técnico aprendido para alguma finalidade produtivista. O movimento humano é a expressão real da pessoa, isto significa incluir toda sua dimensão. A forma humana de sentir, de pensar, de emocionar ou compreender o mundo que o circunda, é codificada através da expressividade motriz, demonstrada a todo instante, em todo o gesto humano. Utilizamos aqui uma frase de

\section{"A forma humana de sentir, de pensar, de emocionar ou compreender o mundo que o circunda, é codifi- cada através da expressividade motriz, demons- trada a todo instante, em todo o gesto humano".}


Lapierre (1988-B) que ajuda a clarear como pensamos: Não há ato gratuito; tudo o que é feito espontaneamente tem um sentido, mesmo se este escapa ao próprio interessado. Sob o conteúdo manifesto ocultasse um conteúdo latente $(\mathrm{p}, 10)$.

A maioria dos autores como Winnicott (1975), Mahler (1993), Morizot (1988), Biagini (1988), Reich (1975), Bertherat (1990), Lapierre e Aucouturier (1984), entre outros, direcionam uma formação de caráter pessoal exclusivamente para terapeutas que tratam do exercício da psicanálise ou terapeutas do corpo, como cinesiterapeutas, psicomotricistas relacionais e reeducadores clínicos, esquecendo-se que nas outras áreas

"Se profissionalmente compreende-se o corpo como also separado, segmentado, será que se pode admiti-lo pessoalmente como uno, ou seja, uma totalidade?" da saúde também existem relações humanas. Lapierre e Aucouturier (1984) que diz: Assim
Sendo assim a conhecida citação de como o psicanalista que unicamente pode formar-se através de sua própria análise didática, o psicomotricista não pode formar-se a não ser a partir de uma experiência íntima de sua própria análise psicomotora (p.05). Também deve ser ampliada para as outras áreas da saúde, uma vez que a relação profissional perpassa pela relação pessoal.

Possuir um autoconhecimento da própria gestualidade, decodificar os desejos, conhecer as próprias facilidades e dificuldades, ser capaz de observar a si mesmo na relação com o outro, desenvolver tempo de escuta, ser agente de comunicação tônico-gestual, sem que necessariamente haja movimento dinâmico, são alguns componentes que dão significancia à relação pessoal e que necessariamente implicam em sucesso na relação profissional.

Freud (1973) e Fromm (1990) ressaltam que, se as forças inconscientes se tornam conhecidas, esta mudança possui um efeito direto sobre o ser; ocorre um aumento de energia e a pessoa está capacitada a viver com maior liberdade e alegria, porque é conhecedora de si mesma, por conseqüência consegue se fazer feliz ou prejudicar-se menos.

Nesse sentido, podemos entender que unicamente estaria capacitado a compreender o outro quem consegue compreender primeiro a si mesmo, bem como que o pressuposto para o crescimento pessoal se dá pelo conhecimento das fragilidades e das potencialidades pessoais. O acesso para esse autoconhecimento é a via corporal, ou seja, as vivências e experiências corporais em interação dinâmica com os iguais, com os objetos e ainda consigo mesmo.

Segundo Aucouturier (1986), a formação pessoal trata de uma competência relacionai com o outro. São as vivências corporais orientadas por um formador que seja continente dos trabalhos desenvolvidos, que poderá favorecer a tomada de conhecimento da própria corporeidade no universo relacionai.

Assim, considerando que a relação do profissional da área da saúde acontece com o outro, seja em relação dual ou coletiva e, como ressalta Bertherat (1990), não é um ser cefálico e acorpóreo, que desconsidera sua totalidade reduzindo-a à racionalidade. Então podemos compreender que os trabalhos de autoconhecimento através da via corporal urgem cada vez mais em uma sociedade que não consegue reconhecer o próprio movimento e perde o conhecimento da força expressiva nas relações humanas.

\subsection{A CONCEPÇÃO DE CORPOREIDADE \\ E A FORMAÇÃO CORPORAL DO PROFISSIONAL DA SAÚDE}

A concepção de corporeidade pode ser abordada sob vários focos interpretativos que buscam compreendê-la na ação humana, podendo ser de ordem psicanalítica, antropológica, física, biológica ou psicopedagógica. São determinantes para possuirmos clareza de qual paradigma se instituiu socialmente dominante na forma de pensar e também de agir das pessoas. Entendendo essa questão como componente fundamental nas reflexões que abordam a formação corporal para os profissionais da saúde. Vamos abordá-la sob dois focos centrais que são, de um lado, o paradigma racionalista e, de outro, o humanista.

No exercício profissional, predominam ações de caráter técnico e mecanicista. As intervenções realizadas compacientes, alunos e/ ou praticantes são racionalizadas e técnicas. Essa forma de intervenção, se, por um lado, mostra-se eficiente pela segurança do ato técnico científico, por outro se torna mecânica e calculista, contribuindo para uma relação humana frágil e deficiente. 
Segundo Mauss (1974), os gestos corporais são maneiras como o ser humano ou a sociedade, de maneira tradicional, sabem servir-se de seus corpos. Todo o gesto humano corresponde a uma técnica aprendida e aperfeiçoada socioculturalmente. Mauss explica: Cada sociedade tem hábitos que lhes são próprios (p.213). Os hábitos variam não simplesmente com os indivíduos e imitações, mas sobretudo com as sociedades, as educações, as conveniências, as modas e com os prestígios. Mauss complementa: E preciso ver técnicas e a obra da razão prática coletiva e individual, ali onde de ordinário vêem-se apenas a alma e suas faculdades de repetição (p.214).

A visão completa do gesto humano corresponde ao sentido étnico, que surgem as técnicas do corpo assim como as técnicas profissionais. O corpo é o primeiro e mais natural instrumento do ser humano. Para Mauss, o comportamento corporal é ajustado conforme o que aprendemos e o que se instituiu culturalmente como certo e errado. Afirma que tudo o que se realiza corporalmente é comandado por signos externos que se transformam em comportamentos psicológicos internalizados.

Considerando as idéias de Mauss, podemos entender que as técnicas profissionais são técnicas corporais que se constituem não somente de um aprendizado corporal, mas de uma cultura corporal que aprova e recomenda como certo e seguro, ou desaprova como desapropriado e inseguro.

Estas são as marcas da razão na cultura corporal moderna, onde o pensamento racional, lógico e linear são os principais transmissores do binômio efeito e causa. $\mathrm{O}$ pensamento lógico da cultura moderna é o raciocínio matemáti$\mathrm{co}$, que quantifica e mensura, se tomando objetivo e direto nas soluções que apresenta. A busca de respostas seguras e lógicas se identifica com a objetividade do profissional com o outro, entendendo que, através das técnicas, o procedimento será seguro e confiável.

Segundo Morin (1990), o paradigma da complexidade (pensamento pós-moderno) apresenta instabilidades nessa linearidade que sugere confiança e segurança. Morin explica:

"Não é preciso acreditar que a questão da complexidade se coloca apenas hoje a partir de novos desenvolvimentos científicos. É preciso ver a complexidade onde ela aparece em geral ausente, como, por exemplo, na vida quotidiana" (p.69).

Morin ensina que a vida social dos indivíduos é de fato uma vida onde cada um representa vários papéis sociais, segundo o que é em casa, no trabalho, com amigos ou ainda com desconhecidos. Vê-se que cada pessoa tem uma multiplicidade de identidades, uma multiplicidade de personalidades nela própria, um mundo de fantasmas e de sonhos que acompanham a sua vida. Esse é o paradigma da complexidade, onde de fato não existe linearidade de comportamentos, tampouco uma única forma de pensar. O comportamento humano toma a posição simbólica que corresponde ao ambiente, tempo e pessoas que fazem relação.

Assim, o conhecimento da corporeidade se mostra como condição para entender em profundidade o comportamento, o que é expressado e o que o ambiente transmite. Supera-se a condição passiva, irreflexiva e aperceptiva pessoal e externa, para uma posição de agentes de mudança e provocadores de novas formas de pensar e de compreender o paradigma da complexidade, que é a vida.

As técnicas corporais aprendidas tradicionalmente tomam nova dimensão quando se consegue percebê-las como simples instrumentos, passando a agir nas relações humanas cientes de que o sucesso das técnicas dependem exclusivamente dos vínculos sócio-afetivos. Em outras palavras, ter ciência da própria corporeidade é saber transmitir pela via relacionai condições de segurança e confiança nas relações profissionais com o outro.

Não se trata de uma mudança de enfoque nas técnicas científicas que fazemos uso, mas entender que fundamentalmente nas relações humanas o conhecimento da corporeidade significa um novo olhar sobre o outro. Uma visão que dispensa o absurdo do procedimento frio e calculista através da técnica mecanicista e automatizada, mas que prioriza, através da compreensão do sentimento do outro, a justeza do conhecimento necessário para a obtenção do crescimento pessoal.

\section{CONSIDERAÇÕES FINAIS}

Ao tratarmos do tema que sugere uma

\section{"Possuir um autoconhecimento da própria gestualidade, decodificar os desejos, conhecer as próprias facili- dades e dificulda- des, ser capaz de observar a si mesmo na relação com o outro, desenvolver tempo de escuta, ser agente de comunicação tônico-gestual, sem que necessariamente haja movimento dinâmico, são alguns componen- tes que dão significancia à relação pessoal e que necessaria- mente implicam em sucesso na relação profissio- nal"}


formação pessoal para os profissionais da saúde, dois aspectos devem ser ressaltados. O primeiro trata das influências do entendimento sobre o gesto humano, sua expressividade que é conhecida e desconhecida e, segundo, entender a questão da corporeidade.

Quanto ao primeiro aspecto, fica claro que não pode haver diferenças entre as formas pessoal e profissional de conceber o corpo, pois como explica Biagini (1988) o ser humano é uno, inteiro e global. Significa compreender a totalidade como a fusão dos aspectos relacionais e funcionais, pois o corpo não está separado do pensamento ou vice-versa.

\begin{abstract}
"A técnica toma outra dimensão na relação entre pessoas quando ela é natural e humana. Essa dimensão da técnica não pode ser aprendida em leituras de livros ou ainda pela simples observação de quem está realizando-a".
\end{abstract}

$\mathrm{Na}$ concepção de Biagini, não existe mudança profissional sem haver primeiro uma mudança em nível pessoal. Significa entender que o conhecimento e as técnicas profissionais são, sobretudo, ações não separadas da sensibilidade pessoal.

O segundo aspecto ressalta a subjetividade da forma de pensar e se comportar das pessoas. É refletida e confrontada com a linearidade lógica e racional, entendida até então como correta; assim, novos signos psicológicos vão compor a forma atual de pensar o ser humano e as suas relações com o mundo.

O corpo e o movimento humano necessitam de um entendimento profundo e concreto para além do conhecimento funcional. As técnicas funcionais são questionadas e dão espaço, como coloca Lapierre (1988-B), "para uma relação natural entre as pessoas" (p.11).

Também Mauss (1974) ensina que a técnica corporal existe em todo comportamento humano e condiz com a história cultural do corpo. É a história natural e faz parte da vida humana. A técnica toma outra dimensão na relação entre pessoas quando ela é natural e humana. Essa dimensão da técnica não pode ser aprendida em leituras de livros ou ainda pela simples observação de quem está realizando-a. Participar de vivências concretas com o próprio corpo, possibilita compreender o real significado do comportamento e refletir sobre o mesmo, obtendo outro entendimento sobre o gesto corporal, conhecendo-o através da reflexão pessoal.

A formação pessoal que tratamos nessa reflexão desperta novo olhar pessoal, que não é imposto nem dirigido, ninguém ensina como fazê-lo, ele têm acima de tudo a marca pessoal, individual. É um autoconhecimento que sugere mudanças sobre a forma de ser com os outros.

A partir do conhecimento das fragilidades, saber que erramos, que temos fantasmas, que nos emocionamos, que temos sentimentos particulares, também vamos entender que o outro os possui em menor ou maior proporção e, seguramente, diferentes. Isso possibilita conceber uma relação de compreensão sobre a outra pessoa que nos procura e que se serve de nós para seu crescimento.

Cabe ressaltar que a intervenção do profissional também não se pode basear nesse único pilar, o conhecimento técnico específico é fundamental e não pode ser descartado sob pena de estar agindo empíricamente. O que deve ficar claro é que existam pontos de equilíbrio nas intervenções profissionais, justeza e equilíbrio pessoal para conseguir tratar o outro, não o contrário, que significa utilizar do outro para fins terapêuticos pessoais.

Somente com o entendimento de que as expressões pessoais tomam parte do conjunto das ações, podemos ajustarmos à concepção interativa de desenvolvimento humano. Isso significa qualidade na presença e disponibilidade do profissional como componentes determinantes para o desenvolvimento do outro. Esses predicados se encontram na própria pessoa, basta que se saiba a via de acesso que facilita sua decodificação.

REFERÊNCIAS BIBLIOGRÁFICAS

AUCOUTURIER, Bernard e Cols. A prática psicomotora, reeducação e terapia. Porto Alegre: Artes Médicas, 1986.

AUCOUTURIER, B. \& LAPIERRE, A. Fantasmas corporais e prática psicomotora. São Paulo: Manole, 1984.

BERTHERAT, Thérèse. $O$ correio do corpo. Novas vias da antiginástica. São Paulo: Martins Fontes, 1990.

BIAGINI, Angela. Que jogo jogamos? In: Congresso Brasileiro (3. : 1988: Porto Alegre) e I Seminário Internacional de Psicomotricidade. 
Psicomotricidade: seu objeto, seu espaço, seu tempo. Porto Alegre: Ed. da UFRGS, 1988.

FREUD, Sigmund. Fragmentos da análise de um caso de histeria. Três ensaios sobre a teoria da sexualidade. Rio de Janeiro: Imago, 1973. v. 7. (Edição Standard Brasileira das Obras Completas de Sigmund Freud, 23 v.)

FROMM, Erich. A descoberta do inconsciente social. São Paulo: Manole, 1990.

LAPIERRE, André. O corpo e o inconsciente. In: Congresso Brasileiro (3. : 1988: Porto Alegre) e I Seminário Internacional de Psicomotricidade. Psicomotricidade: seu objeto, seu espaço, seu tempo. Porto Alegre: Ed. da UFRGS, 1988-A.

. Psicomotricidade relacionai. In:

MAUDIRE,

Paulette. Exilados da infância: relações criativas e expressão pelo jogo na escola. Porto Alegre: Artes Médicas, 1988-B.

MAHLER, Margaret et al. O nascimento psicológico da criança: simbiose e individuação. Porto Alegre: Artes Médicas, 1993.

MAUSS, Marcel. Sociologia e antropologia. São Paulo: Ed. pedagógica e universitária da Universidade de São Paulo, 1974.

MORIN, Edgar. Introdução ao pensamento complexo. Lisboa: Publicações do Instituto Piaget, 1990.
MORIZOT, Regina. O corpo do terapeuta. In: Congresso Brasileiro (3.: 1988: Porto Alegre) e I Seminário Internacional de Psicomotricidade. Psicomotricidade: Seu objeto, seu espaço, seu tempo. Porto Alegre: Ed. da UFRGS, 1988.

NEGRINE, Airton. Aprendizagem e desenvolvimento infantil: simbolismo e jogo. Porto Alegre: Prodi1, 1994. V.1.

SANTIN, Silvino. Educação física: da alegria do lúdico à opressão do rendimento. Porto Alegre: Ed. EST UFRGS, 1995.

REICH, Wilheim. A função do orgasmo. São Paulo: Brasiliense, 1975.

\section{UNITERMOS}

Formação pessoal; corpo, totalidade, profissional da área da saúde.

*Atos Falkenbach é mestrando em Ciências do Movimento Humano na UFRGS. Professor de Psicomotricidade da Faculdade de Educação Física do IPA e do Colégio Nossa Senhora das Graças. 